Diabetologia 11, 139-145 (1975)

(c) by Springer-Verlag 1975

\title{
Diurnal and Seasonal Variation in Oral Glucose Tolerance: Studies in the Antarctic
}

\author{
I. T. Campbell, R. J. Jarrett and H. Keen \\ British Antarctic Survey and Unit for Metabolic Medicine, Guy's Hospital, London, England
}

Received: August 22, 1974, and in revised form: January 24, 1975

\begin{abstract}
Summary. Oral glucose tolerance tests were performed in 12 young men in the Antarctic. Tests were done in the morning and afternoon at three monthly intervals (March, June, September, December). The characteristic diurnal variation in glucose tolerance persisted throughout the year, but was greater in the warmer months (March and December). There were significant seasonal differences in glucose tolerance; blood glucose values were lowest, both morning
\end{abstract}

and afternoon, in December (midsummer). In one pair of tests performed during a reversal of normal sleep/activity pattern, the direction of the normal diurnal variation of glucose tolerance was also reversed.

Key words: Oral glucose tolerance, diurnal variation, seasonal variation antarctic.
Diurnal variation in oral glucose tolerance has been described by several authors $[23,3,12,13,1]$ and is now a well recognised phenomenon. The magnitude and the nature of the variation has been investigated in relation to obesity, age, degree of glucose intolerance $[13,20,26]$, and the insulin response $[11,4,26]$. Similar diurnal variation has also been demonstrated in intravenous glucose tolerance [24].

All these investigations have, however, been done over a limited period and in relation to a "normal" day/night cycle and an activity pattern which was governed accordingly. In the investigation described in this paper the opportunity was taken to observe both seasonal and diurnal changes in glucose tolerance in a population of scientists and technicians spending a year (1972) on an Antarctic base (Halley Bay) where there were periods of continuous daylight and continuous dark.

\section{The Environment}

As the setting in which this investigation took place is a little unusual a brief description of it is necessary.

Halley Bay is situated on the Caird Coast of the Weddell Sea (Lat. $75^{\circ} 31^{\prime}$ S long. $26^{\circ} 42^{\prime} \mathrm{W}$ ) some 900 miles from the South Pole. The base itself consists of a collection of huts, which over the years have become drifted over with snow. They are now about $30 \mathrm{ft}$. underground and are accessible down shafts which are extended periodically as the accumulation increases. In 1972 the base was occupied by 22 men who were engaged principally in the study of upper atmosphere physics, meteorology and magnetism.

Being some distance below the Antarctic Circle the day/night pattern consists of three months (November to January) when the sun is continually above the horizon, three months (early May to early August) when the sun is continually below the horizon and two transitional periods. There is a period of about $1-2$ months around midwinter when it is continually dark. Midwinter is 21st June, midsummer 21st December, the spring equinox 21st March and the Autumn equinox 21st September.

Outside temperatures vary from around $-40^{\circ} \mathrm{C}$ during the winter months to $0^{\circ} \mathrm{C}$ at midsummer. Inside the base the ambient temperature was usually between $5^{\circ}$ and $20^{\circ} \mathrm{C}$.

All personnel had their own specific tasks to perform - tractor mechanic, cook, geophysicist, etc. In addition, all helped with the domestic chores and routine base jobs - scrubbing floors, laying tables, transporting food boxes and fuel drums and raising buried stores. Life was based on a $24 \mathrm{hr}$ routine, with meals served at specific times and scientific observation and radio contact with the outside world also following a strict schedule.

Norman (1965), working at Halley Bay in 1959, investigated activity patterns in four subjects. In March, $16 \%$ of the subjects' time was spent out of doors; in June $7 \%$, September $4 \%$ and December $13.5 \% \mathrm{He}$ pointed out that in March much time is spent outside preparing for the winter and, although the sun returns in August, September is the coldest month of the year, with a mean temperature of $-35^{\circ}$ C. It is more similar to the winter months than is March, with a mean temperature of $-20^{\circ} \mathrm{C}$. Using an "activity diary card" technique and taking metabolic values from the literature [22] he found a mean energy expenditure of $3,770 \mathrm{Kcals} / 24 \mathrm{hrs}$ during the warmer months (October to April) and 3,120 Kcals during the colder, dark months (May to September). 


\section{Materials and Methods}

The subjects were all fit, healthy young men aged between 22 and 30. Average age in January 1972 was 24 years, average height $182 \mathrm{cms}$, average weight in March $73 \mathrm{~kg}$, June $72 \mathrm{~kg}$, September $72 \mathrm{~kg}$, and December $72.5 \mathrm{~kg}$.

\section{Base Programme}

Morning and afternoon glucose tolerance tests (GTTs) were done on 12 subjects at midwinter, midsummer and the spring equinox and on ten subjects at the autumn equinox.

Tests were started at $8.00 \mathrm{hrs}$ and $16.00 \mathrm{hrs}$ as close to midsummer, midwinter and the two equinoxes as possible. Six subjects were tested in the morning and the other six that afternoon. The second test was carried out 3-7 days later, again all subjects being tested on the same day.

For the morning test subjects were starved from midnight of the previous day; on the day of the afternoon test they had no food after a light breakfast at $8.00 \mathrm{hrs}$. No other specific dietary preparations were made, but all subjects were on the same diet, which remained the same throughout the year and contained the $150 \mathrm{~g}$ of carbohydrate per day recommended to precede a glucose tolerance test [14].

Subjects sat quietly during the test and did not smoke. Venous blood was taken through an indwelling venous cannula. After a fasting blood sample had been taken, $50 \mathrm{~g}$ of anhydrous D-glucose was given in $250 \mathrm{ml}$ of water and $10 \mathrm{ml}$ of venous blood subsequently taken at $0.5,1.0,1.5,2.0$, and $2.5 \mathrm{hrs}$.

The blood was taken into EDTA (lithium sequestrene) tubes and stored on ice. After the test $2 \times 0.1$ $\mathrm{ml}$ aliquots of whole blood were pipetted into plain plastic tubes containing $1 \mathrm{ml}$ of $2 \%$ perchloric acid and frozen for shipment to the U.K. for glucose estimation.

The remainder of the sample was centrifuged and the plasma pipetted off and frozen for shipment to the U.K. to be analysed for insulin and growth hormone.

\section{Field Programme}

In addition to the main project carried out over the course of the year, five individuals and an observer spent a period of one week in a hut and a tent, about three miles from base, immediately after midwinter and during the period of continuous darkness. Apart from the observer, none had watches and as a group adopted their own sleep/activity pattern. Radio contact was maintained with base once a day, by the ob- server, at randomised times which had been previously arranged with the radio operator on base.

Very little outside activity was possible with an outside temperature varying between $-35^{\circ} \mathrm{C}$ and $-45^{\circ}$ C. Apart from a short walk of $1 / 2 \mathrm{hr}$ early in the week the subjects spent their time sitting reading, talking and playing cards.

Their sleeping pattern was disrupted the first day by not arriving at the campsite until $4.00 \mathrm{hrs}$. They adopted a $25-26 \mathrm{hr}$ day and at the end of five days their day/night pattern had almost completely reversed - getting up at $17.00 \mathrm{hrs}$ and going to bed at 6.00 hrs. GTTs were done on the five subjects and the observer at $16.00 \mathrm{hrs}$ on the fifth day, for which test the subjects had to be woken up, and at $8.00 \mathrm{hrs}$ on the eighth day, after the subjects had been up for $12 \mathrm{hrs}$. Venous blood was taken and $2 \times 0.1 \mathrm{ml}$ aliquots stored in $1 \mathrm{ml} 2 \%$ perchloric acid. It was not possible to save plasma for insulin assay.

\section{Analysis}

Analysis of the samples for glucose was done in the U.K. between June and October 1973 using a glucose oxidase technique on an Auto-Analyser (see appendix 1).

In order to avoid interassay variation, all the samples from each subject were measured in one batch, processed on the Auto-Analyser in random order; a mean value was taken of the duplicate samples of each specimen.

\section{Results}

Because of the demands made on them by base duties two subjects were unable to participate in the glucose tolerance tests performed in September and due to a technical failure in analysis the afternoon results on another subject for June were lost. The data available therefore is for twelve subjects in March and December, 11 subjects in June and 10 subjects in September.

\section{Diurnal Variation}

The results of the eight GTTs done over the year on base are presented in Fig. 1. The characteristic difference between morning and afternoon tests described by previous authors is seen to persist throughout the year, but its magnitude varied from one time of the year to another. In March, the difference was only significant at 1.5 and $2 \mathrm{hrs}$; in June only at 2 hrs and in September not at all. In December there 
was a significant difference at $1 \mathrm{hr}$ and $1.5 \mathrm{hrs}$. In this population morning and afternoon differences decreased progressively from March to June and September and increased again in December. In all periods mean afternoon levels at $0.5 \mathrm{hrs}$ were lower than corresponding morning levels, rising to a peak at $1 \mathrm{hr}$ and crossing the morning curve between $0.5 \mathrm{hrs}$ and $1 \mathrm{hr}$.
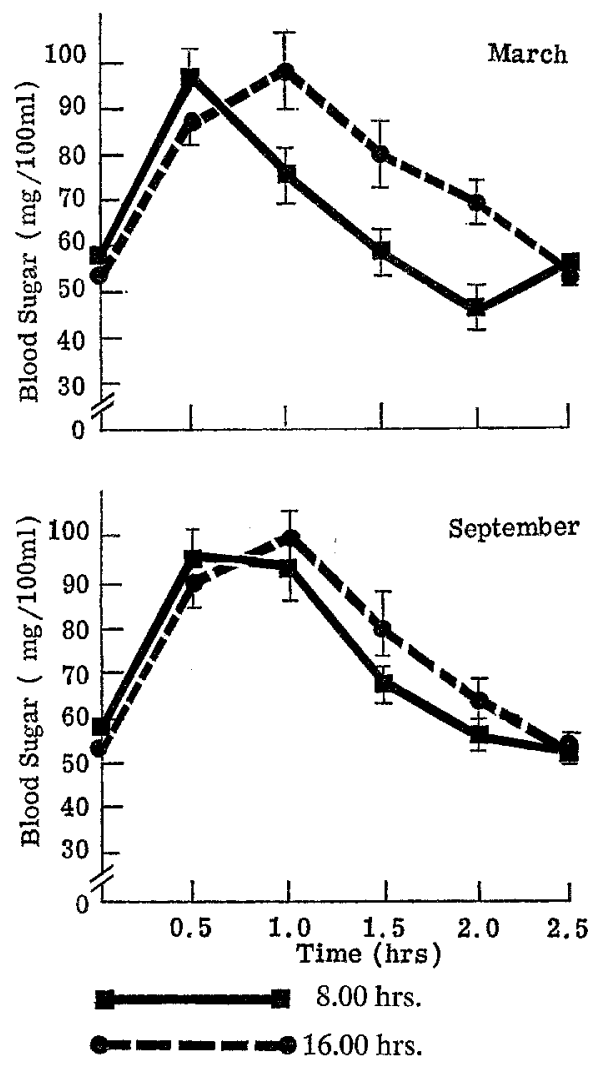

Fig. 1. Mean ( \pm SEM) blood sugars in oral glucose tolerance tests by time of day and by season

\section{Seasonal Differences}

The mean values for all afternoon tests and all morning tests are shown in Fig. 2. December curves for both morning and afternoon are lower than at other times of the year. Differences between June (midwinter) and December (midsummer) were determined by factorial analysis on the 11 subjects for whom the data was complete. Differences were significant $(p<0.05)$ for both morning and afternoon values fasting and at $0.5 \mathrm{hrs}$ and $1.0 \mathrm{hrs}$; for the morning values only at $1.5 \mathrm{hrs}$. There was no significant difference at $2.0 \mathrm{hrs}$ and $2.5 \mathrm{hrs}$.

Morning tests done in June and September appeared to peak between $0.5 \mathrm{hrs}$ and $1 \mathrm{hr}$ - later than the morning tests in March and December which reached a peak at $0.5 \mathrm{hrs}$ or earlier.

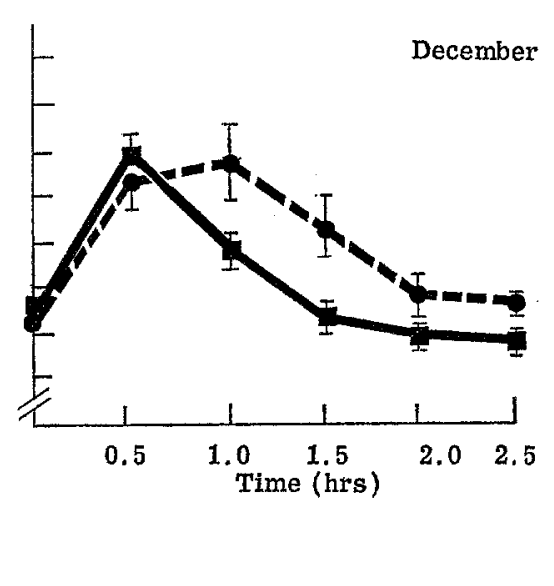

\section{Field Programme}

The results obtained on the six subjects who took part in the project off base at midwinter are presented in Fig. 3. The test at $16.00 \mathrm{hrs,} \mathrm{immediately} \mathrm{after}$ rising, gave results similar to those usually seen in morning tests. The blood glucose response at 8.00 hrs, after subjects had been up for $12 \mathrm{hrs,} \mathrm{showed} \mathrm{the}$ relatively impaired tolerance of afternoon tests. The

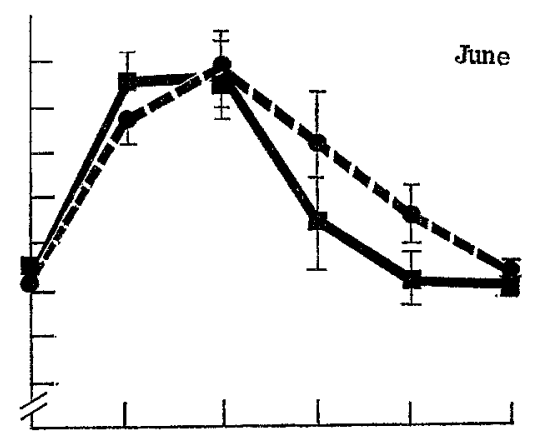

differences between morning and afternoon levels were statistically significant at all time points after $0.5 \mathrm{hrs}$. In addition, the blood sugar levels attained immediately after getting up are low compared with the ones found on base at midwinter. However, as two different groups of subjects are involved, the two sets of results are not directly comparable.

\section{Discussion}

The Antarctic offers a unique opportunity to study a population under relatively standard conditions for extended periods. It is possible to make long term observations on physiological parameters and to record the response to unusual situations - periods of 
continuous dark, continuous light and intense cold [9]. The observations described in this paper demonstrate a seasonal change in glucose tolerance and seasonal changes in the relationship between morning and afternoon tolerance in this environment.
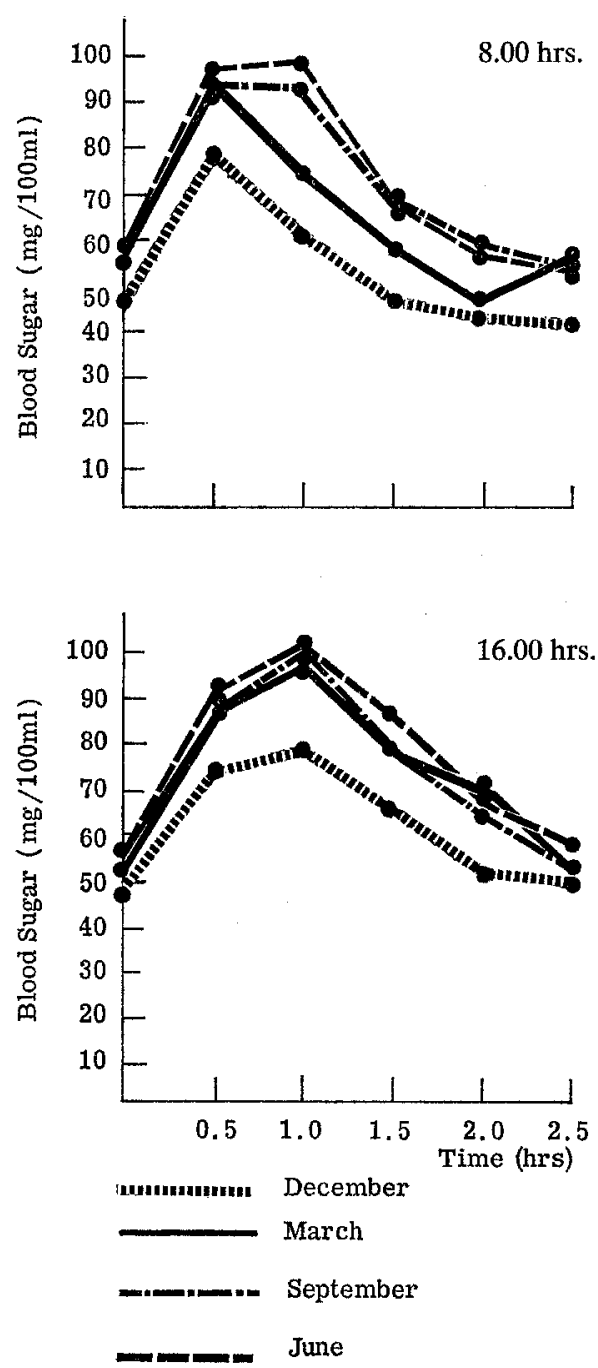

Fig. 2. Mean blood sugars in oral glucose tolerance tests by season

Glycaemia following a standard oral glucose load was lower during the summer than during the other three seasons (Fig. 2). Fasting glucose levels were also lower. A similar observation was made by Fahlén et al., (1971) who studied four groups of men three months after surviving a myocardial infarct. Possible explanations can be sought in seasonal changes in the various conditions that have been shown to affect glucose tolerance - food intake, activity, weight changes, or in factors peculiar to the environment periods of continuous light and continuous dark and large alterations in outside temperatures. All the sub- jects were fit young men so questions of illness and drugs do not arise. The diet was constant throughout the year and contained well over $150 \mathrm{~g}$ of carbohydrate per day; the period of fasting was the same in all cases; mean seasonal weights did not change significantly and energy expenditure records (see appendix 2) show the same levels of activity, albeit in different individuals, over the four seasons. It should be noted, however, that these energy expenditure results differ from previous studies in Polar expeditions, which demonstrated a significant difference in energy expenditure between the summer and winter months while on base [19, 21].

Subjects spent more time out of doors during the summer and their life style was very different from the winter months, when they were cooped up under-

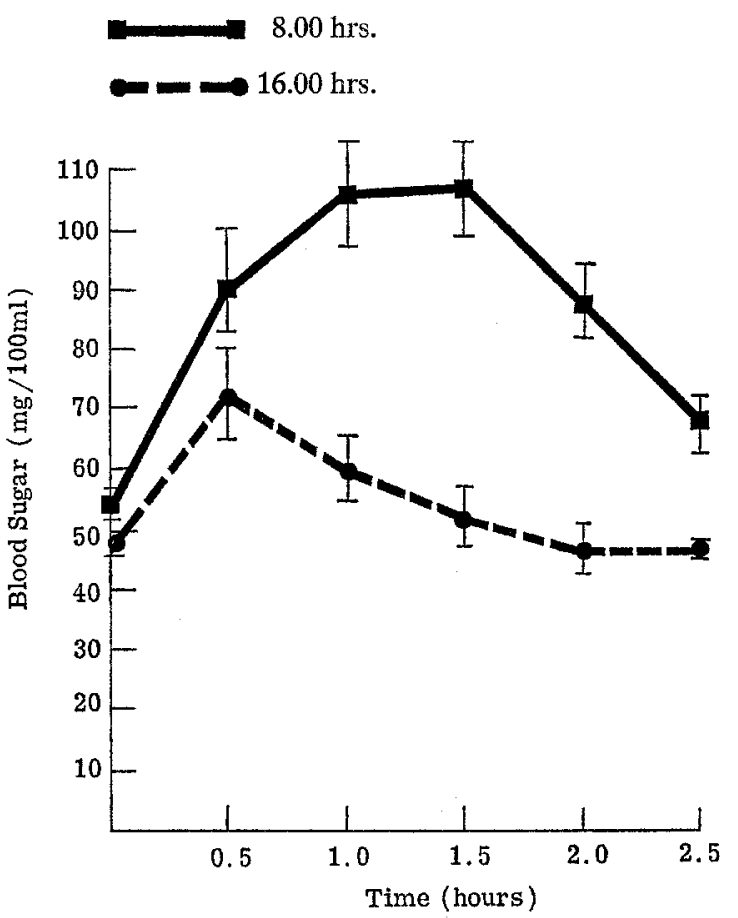

Fig. 3. Mean blood sugars ( \pm SEM) in the two glucose tolerance tests performed during the field programme

ground. Their work did not necessarily take them out very much more than in the winter, but they would go off for walks, skiing or exercising dogs, visiting the coast three miles away and often staying out late into the evening. The effects of $24 \mathrm{hr}$ sunlight and the more active way of life could have some bearing on the improved tolerance. The influence of light has certainly been demonstrated in animal studies, with increased insulin sensitivity and lower blood glucose values during the summer months $[6,25]$.

The other difference between seasons lies in the environmental temperatures. Air temperature at mid- 
summer is usually around zero, but with a very large heat gain from radiation due to the very clear atmosphere and reflection from the snow [5]. Temperatures at the other times of the year when tests were done lay between $-20^{\circ} \mathrm{C}$ and $-45^{\circ} \mathrm{C}$.

The difference between morning and afternoon tolerance is less than has been described in more temperate latitudes; Jarrett et al., (1972) and Carroll and Nestel (1973) found significant differences at all time points after $30 \mathrm{~min}$. The difference between morning and afternoon tolerance is seen to decrease in June and September and increase again in December. In addition, morning tests showed a later peak during June and September than during March and December.

For the five months May to September personnel were totally confined to their subterranean habitat and other than meal times and scientific observations there were no external clues to the time of day. Pressures of time and the burdens of routine were not as great as in a more civilised setting. People often worked in their own time - sometimes late into the night or very early in the morning and often took naps during the day. Lewis and Masterton (1957) noted the irregular sleeping patterns of men on the British North Greenland Expedition during winter and the difficulties encountered by some in getting to sleep at night, despite the long periods of darkness. Difficulty in getting to sleep was a very common complaint at Halley Bay and has been ever since the base was built. The decrease in diurnal variation in glucose tolerance could be due, therefore, to the effects of the subterranean existence and the periods of continuous darkness on the subjects sleep/activity patterns.

\section{Field Experiment}

The experiment conducted away from the base at midwinter showed glucose tolerance of the pattern usually seen in the morning, at $16.00 \mathrm{hrs,} \mathrm{immediately}$ after rising, and relatively impaired tolerance at 8.00 hrs, after the subjects had been up for twelve hours. These patterns are the reverse of those normally seen with respect to the twenty-four hour clock. It should be remembered that the sleep/activity routine adopted by these subjects was entirely spontaneous and not subject to any outside influence, apart from going to bed late the first night.

Response to a glucose load would thus appear to be partly a function of the length of time awake following a period of normal sleep.

The response to glucose immediately on waking appeared to adjust very efficiently to the new "natural" activity pattern, but the response after the subjects had been awake for twelve hours did not adapt to the new period. One wonders what sort of "afternoon" tolerance curve would have occurred if they had been allowed to continue with their $25-26 \mathrm{hr}$ day for a longer period. Would it have "improved", i.e. would the curve have come down, or would it have remained impaired?

Acknowledgements. We would like to thank the stoic subjects of Halley Bay for their co-operation, Mr. Ken Kilbourn for his technical assistance and Mr. Kevin Acheson for food intake and energy expenditure data.

\section{Appendix 1}

For various reasons it was impractical to analyse the samples for blood sugar while in the Antarctic and a method had to be devised for bringing them back for analysis in the U.K. They were therefore stored in $2 \%$ perchloric acid and frozen, thus destroying any enzyme activity that might cause glycolysis.

The results obtained from the Auto-Analyser using a glucose oxidase technique were lower than expected. This was investigated by analysing blood taken during glucose tolerance tests on two normal subjects in the U.K. by three different methods; - the glucose oxidase technique, as used on the Antarctic samples stored in perchloric acid, the ferricyanide micro-reduction method (Technicon method N-9a), on blood stored in fluoride and analysed by ourselves, and a glucose oxidase method, with blood stored in fluoride and analysed by an independent laboratory. This method, apart from not using a protein precipitant, was identical with our own.

Blood was taken initially into EDTA tubes and stored in a refrigerator until the end of the glucose tolerance test, when $0.1 \mathrm{ml}$ aliquots were pipetted into $0.9 \mathrm{ml}$ potassium fluoride for the ferricyanide method and $1 \mathrm{ml}$ of $2 \%$ perchloric acid for the glucose oxidase method in our own laboratory. $2 \mathrm{ml}$ of whole blood was put into fluoride oxalate tubes for analysis by the other laboratory.

The results obtained are shown in Table 1 and the relationship between the ferricyanide technique and the perchloric acid/glucose oxidase technique shown graphically in Fig. 4. The correlation coefficient of the glucose oxidase/ perchloric acid technique and the ferricyanide technique was $0.98(p<0.0001)$.

The values of the ferricyanide method and the glucose oxidase/fluoride method done by the independent laboratory were similar.

It therefore appears that the glucose oxidase estimation of blood glucose done on blood stored in perchloric acid gives an unusually low reading. Thus a figure of $60 \mathrm{mg} / 100$ $\mathrm{ml}$ by the ferricyanide technique would give a figure of 35 $\mathrm{mg} / 100 \mathrm{ml}$ by the glucose oxidase/perchloric acid method, and $100 \mathrm{mg}$ by the ferricyanide technique would give $67 \mathrm{mg} /$ $100 \mathrm{ml}$ on the glucose oxidase. We have no explanation for the lower reading by the glucose oxidase/perchloric acid method. It was thought that the perchloric acid might have inhibited the action of the glucose oxidase, but standards in perchloric acid gave the same reading as those in benzoic acid1.

Possible effects prolonged storage were also investigated.

1 The same difference was also found when whole blood samples were stored in a higher concentration $(3 \%)$ of perchloric acid. 
Samples of blood in perchloric acid have been stored, frozen and unfrozen, in our laboratory for six months and periodic analysis by the glucose oxidase method has given similar results with no trend to increase or decrease.

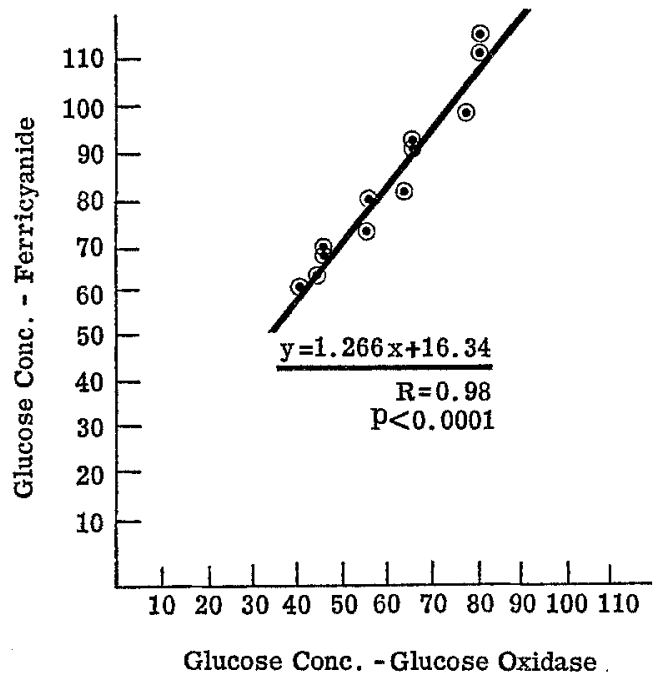

Fig. 4. Calculated regression line for the comparison between the two methods of estimating the blood sugar concentration - ferricyanide reduction and glucose oxidase/ perchloric acid for food intake and energy expenditure for nine of the subjects for the months of March, June, September and December are given in Table 2. The energy expenditure was estimated using the diary card/respirometer technique as described by Passmore and Durnin (1955, 1967). The food intake was measured by individual weighing of all food items eaten and the energy content calculated from the tables of McCance and Widdowson (1969). While the figures do not relate directly to the subjects of the glucose tolerance experiment they are nevertheless representative of the food intake and energy expenditure of the community as a whole. These are factors which are said to affect glucose tolerance $[16,2]$.

\section{References}

1. Ben-Dyke, R.: Diurnal variation of oral glucose tolerance in volunteers and laboratory animals. Diabetologia 7 , 156-159 (1971)

2. Blotner, H.: Effect of prolonged physical inactivity on tolerance of sugar. Arch. Int. Med. 75, 39-45 (1945)

3. Bowen, A. J., Reeves, R. L.: Diurnal variation in glucose tolerance. Arch. Int. Med. 119, 261-264 (1967)

4. Carroll, K. F., Nestel, P. J.: Diurnal variation in glucose tolerance and in insulin secretion in man. Diabetes 22, $333-348$ (1973)

5. Chrenko, F. A., Pugh, L. G. C. E.: The contribution of solar radiation to the thermal environment of man in Antarctica. Proc. Roy. Soc. 155, 243-265 (1961)

Table 1. Comparison of blood sugar levels as measured by 1. Glucose oxidase on blood stored in perchloric acid. 2. Ferricyanide reduction on blood stored in potassium fluoride. 3. Glucose oxidase on blood stored in fluoride oxalate and analysed by an independent laboratory. Venous blood was taken from two normal subjects undergoing oral glucose tolerance tests

\begin{tabular}{llllcccc}
\hline Subject & Method & Fasting & 0.25 hrs & 0.5 hrs & 1 hrs & 2 hrs & 2.5 hrs \\
\hline A & 1 & 40 & 49 & 69 & 48 & 34 & 38 \\
& 2 & 68 & 80 & 98 & 74 & 62 & 64 \\
& 3 & 72 & 88 & 118 & 74 & 50 & 60 \\
\hline B & 1 & 40 & 58 & 72 & 72 & 58 & 56 \\
& 2 & 69 & 90 & 110 & 113 & 91 & 74 \\
& 3 & 60 & 98 & 134 & 132 & 94 & 74 \\
\hline
\end{tabular}

Table 2. Mean energy intake and energy expenditure of 9 individuals (not the subjects in the glucose tolerance experiments) for 1 week during March, June, September and December

\begin{tabular}{lcccc}
\hline & March & June & Sept. & December \\
\hline $\begin{array}{l}\text { Energy intake } \\
\text { (Kcals/24 hrs) }\end{array}$ & 3219 & 2750 & 2886 & 2850 \\
$\begin{array}{l}\text { Energy } \\
\text { expenditure } \\
\text { (Kcals/24 hrs) }\end{array}$ & 3030 & 3040 & 3030 & 3150 \\
\hline
\end{tabular}

Appendix 2

At the same time as the project described was carried out, some of the population at Halley Bay were the subject of an energy balance survey (results to be published). Mean figures
6. Culhane, K.: The use of rabbits in insulin assay. Quart. J. Pharm. 1, 515-533 (1928)

7. Fahlén, M., Odén, A., Björntorp, P., Tibblin, P.: Seasonal influence on insulin secretion in man. Clin. Sci. 41, 453458 (1971)

8. Freinkel, N., Mager, M., Vinnick, L.: Cyclicity on the interrelationships between plasma insulin and glucose during starvation in normal young men. J. Lab. clin. Med. 71, 171-178 (1968)

9. Goldsmith, R., Lewis, H. E.: Polar expeditions as human laboratories. J. occup. Med. 2, 118-122 (1960)

10. Jarrett, R. J.: Problems of the glucose tolerance test. Brit. J. Hosp. Med. 10, 578-580 (1973)

11. Jarrett, R. J., Baker, I. A., Keen, H., Oakley, N. W.: Diurnal variation in glucose tolerance: Blood sugar and plasma insulin levels morning, afternoon and evening. Brit. med. J. 1972 I, 199-201 
12. Jarrett, R. J., Keen, H.: Diurnal variation of oral glucose tolerance: a possible pointer to the evolution of diabetes mellitus. Brit. med. J. 1969 II, 341-344

13. Jarrett, R. J., Keen, H.: Further observations on the diurnal variation in glucose tolerance. Brit. med. J. 1970 IV, 334-337

14. Klimt, C. R. et al.: Standardisation of the oral glucose tolerance test. Diabetes 18, 299-310 (1969)

15. Lewis, H. E., Masterton, J. P.: Sleep and wakefulness in the Arctic. Lancet 1957 I, 1262-1266

16. Lipman, R. L., Raskin, P., Love, T., Triebwasser, J., Lecocq, F. R., Schnure, J. J.: Glucose tolerance during decreased physical activity in man. Diabetes 21, 101107 (1972)

17. Malherbe, C., de Gasparo, M., de Hertogh, R., Hoet, J. $\mathrm{J}$.: Circadian variations of blood sugar and plasma insulin levels in man. Diabetologia 5, 397-404 (1969)

18. McCance, R. A., Widdowson, E. M.: The composition of foods. Medical Research Council. London: H.M.S.O. 1969

19. Norman, J. N.: Cold exposure and patterns of activity at a polar station. British Antarctic Survey Bulletin 6, 1-13 (1965)

20. Oakley, N. W., Monier, D., Wynn, V.: Diurnal variation in oral glucose tolerance: insulin and growth hormone changes with special reference to women taking oral contraceptives. Diabetologia 9, 235-238 (1973)
21. Ohkubo, Y.: Basal metabolism and other physiological changes in wintering members of Japanese Antarctic Research Expedition 1968-1969. Bull. Tokyo med. dent. Univ. 19, 245-269 (1972)

22. Passmore, R., Durnin, J. V. G. A.: Human energy expenditure. Physiol. Rev. 35, 801-840 (1955)

23. Roberts, H. J.: Afternoon glucose tolerance testing: a key to the pathogenesis, early diagnosis and prognosis of diabetic hyperinsulinism. J. Amer. Geriat. Soc. 12, 423-472 (1964)

24. Whichelow, M. J., Sturge, R. A., Keen, H., Jarrett, R. J., Stimmler, L., Grainger, S. L.: Diurnal variation in response to intravenous glucose. Brit. med. J. 1974 I, 488491

25. Young, D. A. B.: Hypothalamic (photoperiodic) control of a seasonal antagonism to insulin in the rat heart. J. Physiol. 178, 530-543 (1965)

26. Zimmet, P. Z., Wall, J. R., Rome, R., Stimmler, L., Jarrett, R. J.: Diurnal variation in glucose tolerance: associated changes in plasma insulin, growth hormone, and non-esterified fatty acids. Brit. med. J. 1974 I, 485-488

Dr. R. J. Jarrett

Dept. of Medicine

Guy's Hospital Medical School

London Bridge SE 19 RT

England 